\title{
Le Lion de Flandre d'Henri Conscience : un destin européen
}

Roberto Dagnino

\section{(2) OpenEdition}

1 Journals

Édition électronique

URL : http://journals.openedition.org/rbnu/648

DOI : $10.4000 /$ rbnu.648

ISSN : 2679-6104

\section{Éditeur}

Bibliothèque nationale et universitaire de Strasbourg

\section{Édition imprimée}

Date de publication : 1 novembre 2017

Pagination : 16-19

ISBN : 9782859230678

ISSN : 2109-2761

\section{Référence électronique}

Roberto Dagnino, "Le Lion de Flandre d'Henri Conscience : un destin européen », La Revue de la BNU [En ligne], 16 | 2017, mis en ligne le 01 juillet 2019, consulté le 12 décembre 2020. URL : http:// journals.openedition.org/rbnu/648; DOI : https://doi.org/10.4000/rbnu.648

\section{(c) (i) (8)}

La Revue de la BNU est mise à disposition selon les termes de la Licence Creative Commons Attribution - Pas d'Utilisation Commerciale - Partage dans les Mêmes Conditions 4.0 International. 

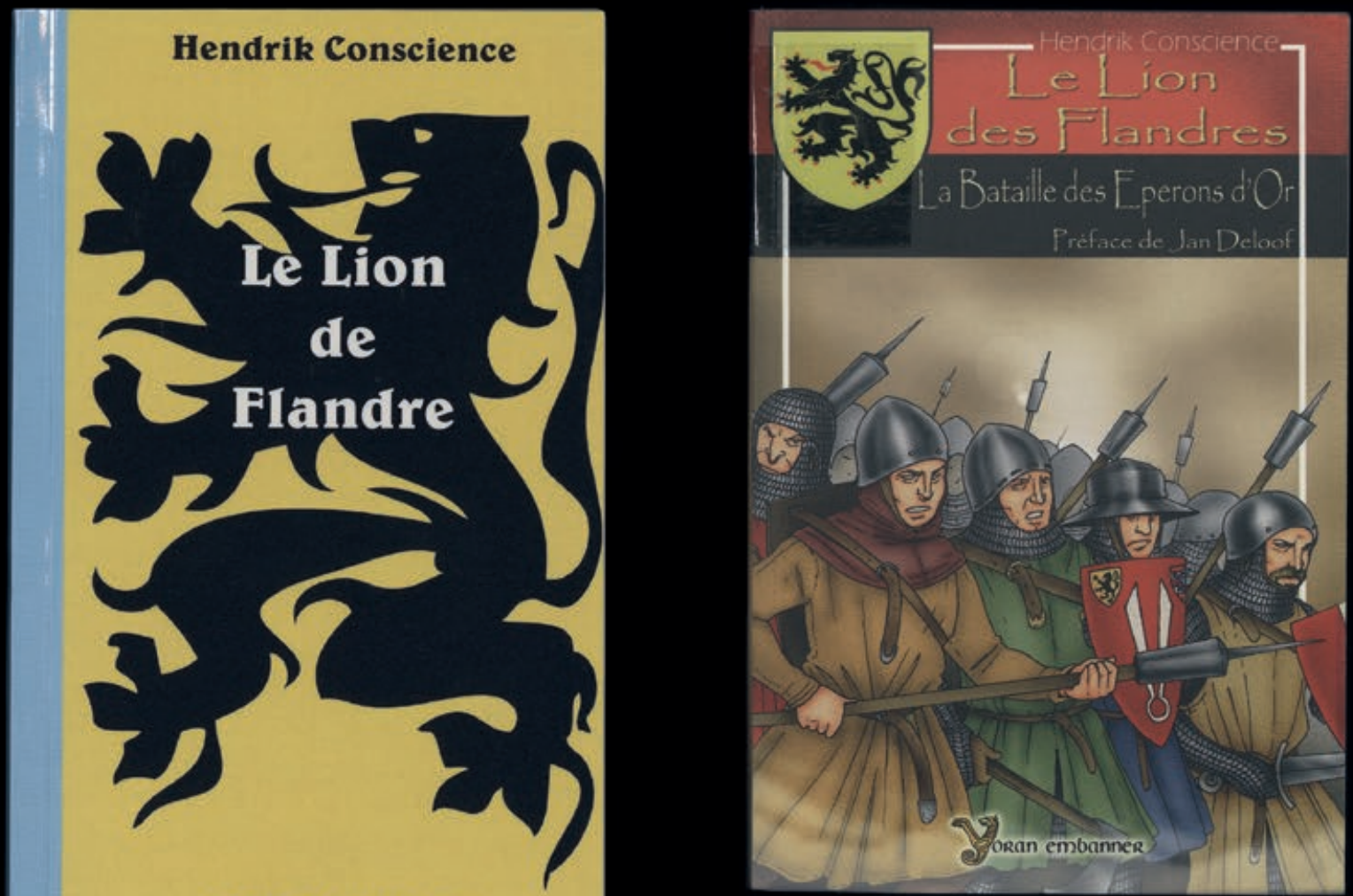

NEL-VERLAG
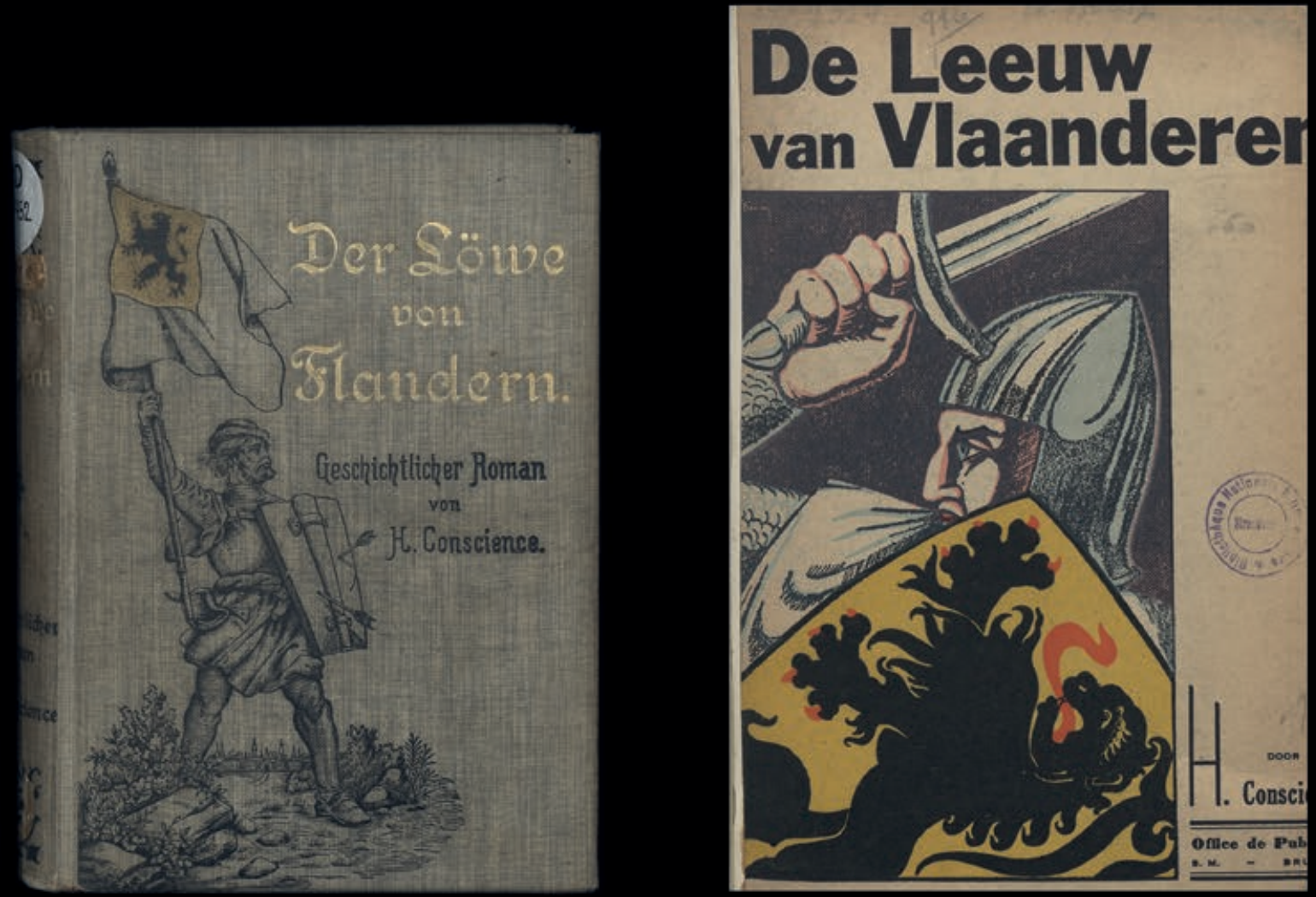

Hendrik Conscience, Le Lion de Flandre, [Strasbourg], NEL-Verlag, [2016] / Henri Conscience, Le Lion des Flandres, Fouesnant, Yoran Embanner, 2007 / Heinrich Conscience, Der Löwe von Flandern. Geschichtliche Erzählung, Graz und Wien,

Verlagsbuchhandlung « Styria », [s. d.] / Hendrik Conscience, De Leeuw van Vlanderen, Bruxelles, Office de publicité, [1941] 


\section{BELGIQUE \\ LE LION DE FLANDRE D'HENRI CONSCIENCE : UN DESTIN EUROPÉEN}

PAR ROBERTO DAGNINO

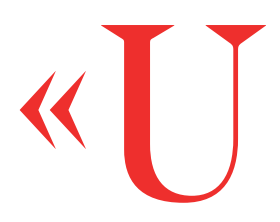

$\mathrm{n}$ film néerlandophone violemment antifrançais " : ainsi s'exprima $L a$ Libre Belgique le 28 janvier 1984 lors de la sortie du film Le Lion de Flandre (De Leeuw van Vlaanderen), mis en scène par l'écrivain et multitalent flamand Hugo Claus. C'était la première - et unique, jusqu'à présent - version filmée du populaire roman historique du même titre publié par Henri Conscience en 1838. Que Claus, considéré comme postmoderne, puisse se lancer dans la transposition d'un roman au potentiel nationaliste, choqua d'ailleurs plus d'un critique, non seulement francophone ${ }^{1}$. Dans une Belgique en voie de fédéralisation, le sujet était explosif. Mais est-ce qu'une lecture purement nationaliste du roman est bien justifiée? Quelles étaient les intentions de Conscience?

À bien y regarder, le roman se caractérise surtout par sa capacité d'adaptation, qui lui a permis de résister aux contextes historiques les plus variés. Que Conscience deviendrait le premier grand auteur de la littérature néerlandophone en Belgique, celui qui « apprit à son peuple à lire », n'était pas gagné à la parution du Leeuw. Dans une Belgique indépendante depuis 1830, l'usage des langues fut déclaré libre, quoique le prestige du français et la fragmentation des dialectes flamands aboutissent bientôt à un monolinguisme francophone. Toutefois, le flamand ne fut pas oublié. Moult initiative fut mise en place pour le promouvoir, sans pour autant imaginer une véritable égalité avec le français. Le gouvernement se lança dans l'uniformisation de l'orthographe et - de fait - dans le rapprochement vis-à-vis du néerlandais, ainsi que dans la sponsorisation de concours littéraires. À Gand, Bruxelles, Anvers et Louvain, plusieurs écrivains et artistes fondèrent des cercles de «taalminnaars », les amateurs de la langue. Parmi eux, Hendrik - ou Henri Conscience, jeune Anversois bilingue, né en 1812 dans le quartier populaire de Sint-Andries.

Formé aux auteurs français, Conscience décida d'appliquer au néerlandais les motifs et les techniques $\mathrm{du}$ romantisme ambiant. Il prit un événement historique presque oublié, la bataille des Éperons d'or de 1302, marquée par la victoire des milices flamandes contre les troupes de Philippe le Bel. Il l'enrichit de détails fictifs tels que l'arrivée finale en « deus ex machina » du comte 
de Flandre - en réalité emprisonné en France - dans son armure dorée qui justifie le sobriquet de «Lion ». Il n'oublia pas un brin de sentimentalisme, avec l'amour entre la fille du comte, Mathilde (Machtheld), et le chevalier Adolphe (Adolf). Pour que le roman arrive au plein succès, il fallut en publier une réécriture en 1842 , avec des scènes d'amour édulcorées pour faire plaisir aux critiques catholiques. Mais le jugement fut à ce moment-là unanime : il s'agissait bien là du premier grand roman flamand, capable enfin de donner à la littérature belge sa portion de visibilité.

On dit littérature belge et ce n'est pas une coquille. Les années 1830 et 1840 furent dominées par l'« unionisme » post-indépendance, visant à donner à la Belgique une légitimité historique. Conscience et les autres «taalminnaars » ne percevaient pas de conflit entre le renforcement de la Flandre et le patriotisme belge. Pour s'affirmer face aux troupes néerlandaises, la Belgique avait fait appel à l'intervention décisive de la France en 1831. Libéré des Pays-Bas, le nouveau-né sur la scène européenne se retrouvait désormais en proie à un nouveau risque d'annexion. Il devenait impératif de souligner la non-assimilabilité de la Belgique à la France. Chaque contribution à la cause flamande impliquait forcément une réaffirmation de l'exception belge.

L'opinion publique ne perçut donc pas de menaces dans l'appel aux lecteurs que Conscience inséra dans la postface du roman : «Flamand, qui viens de lire ce livre, médite bien les faits glorieux qu'il renferme ; songe à ce que la Flandre fut jadis, à ce qu'elle est aujourd'hui, et plus encore à ce qu'elle deviendrait si tu oubliais les saints exemples de tes ancêtres $\|^{2}$. Et le lion prêt à l'attaque sur la page de garde se voulait Lion belge et Lion flamand au même temps. De même, la diffusion des symboles du roman, à partir de la composition, en 1845 par Karel Miry, de l'hymne De Vlaamsche Leeuw (Le Lion flamand), ainsi que de la traduction française par le belge Léon Woquier en 1862, fut saluée avec approbation.

Ce ne fut qu'au $20^{\mathrm{e}}$ siècle, avec son droit à l'auto-détermination des peuples, que le nationalisme des « petites nations » fit son entrée dans l'arène politique européenne. La Belgique n'y resta pas insensible. Le néerlandais y avait obtenu en 1898 la parité. Il fallut le choc de la Première Guerre mondiale et l'acceptation de l'impossibilité d'un État entièrement bilingue pour faire surgir le rêve autonomiste, en Flandre tout autant qu'en Wallonie. La vision d'une Belgique composée par deux régions monolingues était née. Ce fut à ce tournant que les identités commencèrent à glisser du belgicisme vers les régionalismes. Petit à petit, on se réorienta vers une perspective fédéraliste, parfois même indépendantiste voire rattachiste (aux Pays-Bas, à une fantomatique Grande Allemagne ou, selon les points de vue, à la France).

L'œuvre de Conscience participa de cette évolution. Le Lion qui avait été double ne devint que flamand. Dans les personnages français qui attaquent la Flandre, on vit de plus en plus des francophones, des Wallons, des «fransquillons ». Ce fut surtout l'appréciation des éditeurs catholiques qui sauva la réputation de Conscience en France, quoiqu'avec une claire préférence pour sa production plus tardive aux références à la religion et aux tons de «Heimatliteratur» plus explicites. Mais ce «Lion » qui l'avait consacré ne finit pas pour autant dans l'oubli. D'autres aires linguistiques prirent le relais de sa diffusion à l'étranger.

Une position particulière est occupée par la culture allemande, dont les vagues de traductions $\mathrm{du}$ « Löwe » reflètent assez précisément l'évolution politique. Pas moins de deux éditions avaient paru en 1846, à la veille des révolutions de 1848 et de l'élan d'unification de l'Allemagne. Le ton antifrançais plut, certains ne manquèrent pas d'y associer des ambitions pangermanistes. L'élan vers la Première Guerre mondiale renforça encore plus l'intérêt pour la « lutte antifrançaise " des cousins flamands : plusieurs traductions du Lion virent le jour en 1912, 1913 et encore en 1916. Et c'est à la période comprise entre la fin du siècle et la guerre que remonte aussi l'édition autrichienne présente dans le catalogue de la BNU. L'enthousiasme pour le roman ne retomba pas après la défaite et fut ensuite habilement utilisé par le régime nazi pour renforcer l'image des Flamands aux avant-postes germaniques de la lutte contre l'ennemi latin. On compte au moins deux traductions parues pendant la guerre, à côté des rééditions autorisées de l'original néerlandais publiées en Belgique occupée, dont une de 1941 disponible à la BNU.

Le Lion sut une fois de plus s'adapter. Il avait été pangermaniste lorsqu'on lui demandait de l'être, il sut devenir autre chose depuis. Les destins récents du roman sont très variés. Dans l'espace néerlandophone, en faisant exception d'une adaptation critique de 1996 - 
présente à la BNU - et d'une édition académique en $2002^{3}$, ce sont surtout les versions scolaires, pour la jeunesse ou en bande dessinée, qui ont pris le dessus. Les tons tonitruants, l'exagération romantique ainsi que les psychologies superficielles ne sauraient plus satisfaire les goûts d'un public adulte. Les adaptations apparues dans les deux Allemagnes dans les années 1950-1970 révèlent une même évolution ${ }^{4}$. En France, c'est le côté régionaliste qui continue de fasciner et la collection de la BNU en fournit la preuve avec deux rééditions, parues respectivement en 2007 chez l'éditeur breton Yoran Embanner - «solidaire des autres minorités nationales en Europe ", revendique-t-il sur son site web - et en 2016 auprès du Strasbourgeois NEL-Verlag, qui en propose aussi une version allemande.

Un héritage en mode mineur, donc ? Pas forcément. Toute adaptation (et manipulation) est au fond aussi une chance de survie ${ }^{5}$. En outre, les traces $\mathrm{du}$ Lion de Flandre, omniprésentes dans sa terre natale, font partie à plein titre du «nationalisme banal » de cette région. Avec la fédéralisation de la Belgique, le chant de Karel Miry est désormais devenu l'hymne de la Région flamande, dont le drapeau officiel - ainsi que le décor de plusieurs compétitions cyclistes - reprend l'ancien blason des comtes de Flandre : un lion rampant sur fond doré.

Il a été tour à tour symbole de la renaissance flamande, bastion de la spécificité belge, arme contre le français voire otage de rêves séparatistes ou annexionnistes. Aujourd'hui, il se présente en version officielle d'interlocuteur du coq wallon. Ce lion flamand, réanimé il y a deux siècles par le roman de Conscience, est finalement resté très belge, capable de survivre contre toute évidence à l'évolution permanente des identités plurielles de son pays ainsi qu'aux secousses de l’histoire européenne.

\section{NOTES}

1- G. Willems, «De Leeuw van Vlaanderen wil ik zo gauw mogelijk vergeten ", in Journal of Belgian History, XLIII, 2013, p. 178-209

2- H. Conscience, Le Lion de Flandre, Paris, Calmann-Lévy, 1876 [1 1 ère éd. 1862], tome II, p. 284

3- Id., De Leeuw van Vlaanderen, Tielt, Lannoo, 2002

4- C. Hermann, «The Flemish Lion: Oscillating Between Past and Present », in Brems, E. et al. (dir.), Going Double Dutch, Louvain, LUP, 2017, p. 209-226

5- L. Hutcheon, A Theory of Adaptation, New York/Londres, Routledge, 2012, p. 176 